\title{
Wettbewerbsordnung und Monopolbekämpfung
}

\author{
Zum Gedenken an Leonhard Miksch (1901-1950) \\ Hrsg. v. Lars P. Feld u. Ekkehard A. Köhler \\ Mit vier Originalaufsätzen von Leonhard Miksch
}

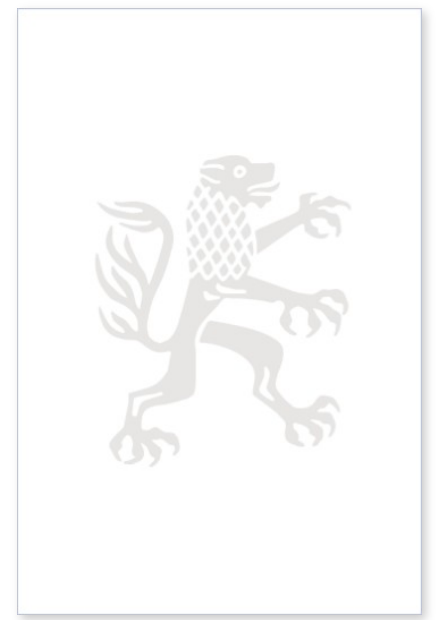

2015. VIII, 175 Seiten. UOrd 67

ISBN 978-3-16-153963-3

DOI 10.1628/978-3-16-153963-3

eBook PDF $64,00 €$

ISBN 978-3-16-151045-8

fadengeheftete Broschur $64,00 €$
Leonhard Miksch (1901 - 1950) ist eine vielschichtige Persönlichkeit innerhalb der Gründungsgeneration der Freiburger Schule. Als Schüler Walter Euckens avancierte er zum engen wirtschaftspolitischen Berater Ludwig Erhards und war maßgeblich an der Entstehung der Sozialen Marktwirtschaft beteiligt. Dieser Band liefert einen Einblick in sein Leben und Werk sowie eine Diskussion seiner wichtigsten Beiträge zur Freiburger Forschungstradition. Sie wurden anlässlich seines 60. Todestages im September 2010 von Uwe Dathe, Nils Goldschmidt, Wernhard Möschel und Ekkehard A. Köhler am Walter Eucken Institut vorgestellt. In einem zweiten Teil werden einige wissenschaftliche Beiträge und Zeitschriftenartikel von Leonhard Miksch abgedruckt. Mit einer Einleitung von Lars P. Feld und Ekkehard A. Köhler sowie Bildtafeln, Faksimiles und einer Bibliographie liefert dieser Band eine erste historische Aufarbeitung des Werks von Leonhard Miksch innerhalb der Freiburger Forschungstradition.

Lars P. Feld Geboren 1966; Studium der Volkswirtschaftslehre; 1999 Promotion; 2002 Habilitation; seit 2010 Direktor des Walter Eucken Instituts Freiburg, Inhaber des Lehrstuhls für Wirtschaftspolitik und Ordnungsökonomik an der Albert-LudwigsUniversität Freiburg und Mitglied des Sachverständigenrates zur Begutachtung der gesamtwirtschaftlichen Entwicklung.

Ekkehard A. Köhler Geboren 1979; 2006 Diplom-Volkswirt; seit 2009 Forschungsreferent am Walter Eucken Institut Freiburg; 2015 Promotion; seit 2016 geschäftsführender Forschungsreferent am Walter Eucken Institut Freiburg.
Jetzt bestellen:

https://mohrsiebeck.com/buch/wettbewerbsordnung-und-monopolbekaempfung-9783161539633?no_cache=1 order@mohrsiebeck.com

Telefon: $+49(0) 7071-923-17$

Telefax: +49 (0)7071-51104 